Research Paper

\title{
Two Nomograms to Select Hepatocellular Carcinoma Patients with Macroscopic Vascular Invasion for Hepatic Resection
}

Yiquan Jiang1 ${ }^{*}$, Hui Tang2 ${ }^{*}$, Zixian Wang 3 , Yuanjing Sun ${ }^{1}$, Wei Meng1, Guoying Wang ${ }^{\bowtie}$, Hua Li1, Shuhong $\mathrm{Yi}^{1}$, Genshu Wang, ${ }^{1}$ Yang Yang ${ }^{1,2}$, Guihua Chen ${ }^{1,2 \bowtie}$

1. Department of Hepatic Surgery and Liver Transplantation Center of the Third Affiliated Hospital, Organ Transplantation Institute, Sun Yat-sen University; Organ Transplantation Research Center of Guangdong Province.

2. Key Laboratory of Liver Disease Research of Guangdong Province, The Third Affiliated Hospital of Sun Yat-sen University, Guangzhou, Guangdong, China.

3. Department of Medical Oncology, Sun Yat-Sen University Cancer Center; State Key Laboratory of Oncology in South China; Collaborative Innovation Center for Cancer Medicine, 651 Dongfeng Road East, Guangzhou 510060, China.

*These authors contributed equally as first authors.

$\triangle$ Corresponding authors: Guoying Wang, E-mail: wanggy3@126.com; Or Guihua Chen, E-mail: chengh1601202@163.com, phone number: +8613544338551, 600 Tianhe Road, Guangzhou 510060, China.

(c) Ivyspring International Publisher. This is an open access article distributed under the terms of the Creative Commons Attribution (CC BY-NC) license (https://creativecommons.org/licenses/by-nc/4.0/). See http://ivyspring.com/terms for full terms and conditions.

Received: 2018.03.06; Accepted: 2018.07.17; Published: 2018.09.07

\begin{abstract}
Background: Hepatocellular carcinoma $(\mathrm{HCC})$ patients with macroscopic vascular invasion (MaVI) have limited lifespans. According to recent studies, surgical treatment may be the most promising option. However, the current staging system does not select patients who will benefit most from hepatic resection.

Study design: A total of 123 patients undergoing hepatic resection for HCC with macroscopic vascular invasion (MaVI) between 2010 and 2014 at The Third Affiliated Hospital of Sun Yat-sen University were selected. We developed nomograms for overall survival (OS) and recurrence-free survival (RFS) using a Cox proportional hazards model. We assessed nomogram model performance based on the concordance index (C-index) and a calibration plot.

Results: The 1- and 3-year overall survival (OS) rates for all patients were $84 \%$ and $71 \%$, respectively. Correspondingly, the 1 - and 3-year recurrence-free survival (RFS) rates were $55 \%$ and $35 \%$, respectively. In the multivariate Cox model, the extent of vascular invasion, tumour count, fibrinogen, HBV DNA load and serum potassium significantly affected prognosis. The C-index of the two nomograms were 0.80 and 0.69 for OS and RFS respectively. Based on our nomogram, patients predicted to have 1-year and 3-year RFS rates of more than $80 \%$ and $56 \%$ had actual 1 -year and 3 -year RFS rates of $81.8 \%$ and $57.1 \%$, respectively, including $9.0 \%$ and $17.1 \%$ of the $\mathrm{HCC}$ patients with $\mathrm{MaVI}$ in our database.

Conclusion: Surgical treatments are a therapeutic option that can provide more survival benefit for HCC patients with MaVI. With the help of our nomograms, selected HCC patients with MaVI can benefit from hepatic resection and have the same survival rate as that for early-stage HCC patients.
\end{abstract}

Key words: Hepatocellular carcinoma, Macroscopic vascular invasion, Hepatic resection, Prognostic predictive model, Nomogram

\section{Introduction}

Hepatocellular carcinoma (HCC), the most common primary malignant tumour of the liver, is considered to be the third leading cause of all cancer-related deaths and the sixth most common cancer worldwide. ${ }^{1,2}$
HCC patients with macroscopic vascular invasion (MaVI) have a limited lifespan. ${ }^{3-5}$ The current Barcelona Clinic for Liver Cancer (BCLC) staging system classifies patients with HCC and MaVI as stage $\mathrm{C}$ and recommends systemic therapy with 
sorafenib. ${ }^{6}$ Therefore, these patients are usually directed to palliative treatments, with poor results. ${ }^{7,8}$

Despite official recommendations, many clinicians do not restrict surgical treatments to early-stage HCC. In fact, studies in several countries have reported surgery to be an effective treatment option for patients in later stages of the disease,,-12 leading to calls to expand the indications for surgical treatment. ${ }^{13,14}$ According to recent studies, surgical treatments, such as hepatic resection or liver transplantation, may be the most promising options for certain patients with MaVI.6,15-17

However, the current staging system still cannot identify patients who will benefit most from hepatic resection. In the present study, we developed nomograms to predict survival for patients with HCC and MaVI based on data from the Third Affiliated Hospital of Sun Yat-sen University. These nomograms can help to identify patients who will benefit most from hepatic resection.

\section{Patients and Methods}

\section{Patients}

A retrospective database of The Third Affiliated Hospital of Sun Yat-sen University was reviewed. A total of 123 patients undergoing hepatic resection for HCC with MaVI between 2010 and 2014 were selected. The HCC diagnosis was determined based on the findings of typical radiologic features in a 4-phase multidetector computed tomography scan or dynamic contrast-enhanced magnetic resonance imaging and finally confirmed by histology after surgery. MaVI was defined as tumours within a vessel that was visible to the naked eye, including the main portal vein and/or portal vein branches and/or hepatic veins and/or inferior vena cava. Patients were preoperatively evaluated by abdominal ultrasonography, thoracic and abdominal dynamic $\mathrm{CT}$, and MRI. The extent of the vascular invasion was accurately assessed by these imaging techniques and was finally confirmed to be within an endothelial lined channel on histology. The inclusion criteria for surgical treatment required patients to have Child-Pugh Class A liver disease. The future remnant liver volume was predicted by CT volumetry in every patient. Patients with resectable tumours and a predicted remnant liver volume of more than $35 \%$ of the total liver volume were offered hepatic resection. Patients with tumor extending into the portal bifurcation or inferior vena cava received tumor thrombectomy and the vessel was closed. Radical resection of the vessel wall and reconstruction was not performed. In most cases, patients with tumor extending into subordinate branches of the major vascular received an anatomic resection. 11 of 123 patients of our database had distant metastasis in lungs but they still requested a hepatic resection and received sorafenib or lung resection after hepatic resection.

\section{Clinicopathologic variables}

Baseline information was comprehensively collected before surgery. Forty-two variables, including tumour size, tumour count, and the extent of vascular invasion, were assessed. The serum concentration of potassium is measured during the first diagnosis of HCC and before the hepatic resection. Patients who receive specific treatment which make great difference in the level of serum potassium, such as a long time solely use of triamterene, furosemide, hydrochlorothiazide, nonsteroidal anti-inflammatory drugs before measure of the concentration of potassium were excluded from the study. For patients who take anti-hypertensive drugs for a long time, they were defined as "hypertension" in the database and were took into univariate analysis. Patients without HBV infection was classified as "HBV DNA copies<100" (which means "negative") during the development of the model. Some studies from Japan divided the portal vein tumor thrombosis into four types: Portal vein invasion (vp1) was defined as an invasion or tumor thrombus distal to the second branch of the portal vein, vp2 as an invasion or tumor thrombus in the second branch of the portal vein, vp3 as an invasion or tumor thrombus in the first branch of the portal vein, and vp4 as an invasion or tumor thrombus in the portal trunk or extending to a branch on the contralateral side. Because it only consider the relationship between portal vein system and the tumor, which does not take into account the hepatic vein system. However, we believe that invasion of hepatic vein can be related with poor prognosis. We further combine the hepatic vein system into these four types according to the order of the branch. In our study, we analysed the prognosis effect of the extent of vascular invasion: Invasion of the main portal vein or inferior vena cava was defined as V4; invasion of the hepatic vein or the first branch of the portal vein was defined as V3; invasion of the first branch of the hepatic vein or the second branch of the portal vein was defined as V2; and invasion of a distant branch of the hepatic vein or portal vein was defined as V1. Factors reflecting liver function were also examined.

\section{Follow-up}

The regular follow-up program started after the patients were discharged from the hospital. Patients were followed up four weeks after discharged for the 
first time, and every 3 months during the first 2 years, every 4 months during the third year thereafter. Follow-up examinations included laboratory tests (including serum alpha-fetoprotein (AFP), liver function, and blood tests), abdominal ultrasonography, and contrast-enhanced CT.

\section{Statistical analysis}

Univariate and multivariate analyses of the factors associated with patient survival were assessed using Cox proportional hazards models. The survival nomograms are based on the multivariate analysis. Hazard ratios are presented with 95\% CI. The nomograms were validated using the concordance index (C-index) and calibration plots. A bootstrap method was also added for further validation. We further split the patients randomly into $70 \%$ cases for development and $30 \%$ cases for validation. The C-index measures the probability of concordance between predicted and observed survival, similar to the area under the receiver operating characteristic curve (ROC) for censored data. The $\mathrm{C}$-index can range from 0.5 to 1.0, indicating random predictions and perfect concordance, respectively. A calibration plot was used to assess the prediction accuracy of the nomogram by plotting the actual survival against the nomogram-predicted survival probabilities. All statistical analyses were performed using SPSS 23.0 (SPSS, Chicago, IL, USA) for Windows and R software (version 3.4.1) with the rms package version 5.1-1 (http://CRAN.R-project.org/package = rms). A two-sided $P$ value less than 0.05 was considered to be statistically significant.

\section{Results}

During the study period, 123 patients underwent hepatic resection for HCC with MaVI at our hospital. The median follow-up time of our patients was 36 months. The 1- and 3-year overall survival (OS) rates for all patients were $84 \%$ and $71 \%$, respectively. Correspondingly, the 1- and 3-year recurrence-free survival (RFS) rates were $55 \%$ and $35 \%$, respectively. At the time of data collection, 36 deaths (29.3\%) and 79 cases of recurrence $(64.2 \%)$ had been recorded. Descriptive statistics for the database are summarized in Table 1.

The univariate and multivariate analyses of survival are listed in Table 2 and Table 3 for overall survival and recurrence free survival, respectively. Multivariate analysis revealed that the extent of vascular invasion [hazard ratio (HR) 3.39, 95\% confidence interval (CI) 1.85-6.21, $\mathrm{p}<0.01$ ], tumour count (HR 2.20, 95\% CI 1.03-4.70, p = 0.04), fibrinogen (HR 1.42, 95\% CI 1.09-1.85, $\mathrm{p}<0.01$ ), and serum potassium (HR 2.08, 95\% CI 1.41-3.06, p < 0.01) significantly affected OS. The extent of vascular invasion [hazard ratio (HR) 1.49, 95\% CI 1.04-2.11, p = 0.03], tumour count (HR 2.27, 95\% CI 1.35-3.85, $\mathrm{p}<$ 0.01 ), HBV DNA (HR 1.74, 95\% CI 1.10-2.75, p = 0.02), and serum potassium (HR 1.35, 95\% CI 1.01-1.80, $\mathrm{p}=$ 0.04 ) had a significant effect on RFS.

Table 1. Patient demographics and clinical variables

\begin{tabular}{|c|c|}
\hline Characteristic & Value \\
\hline Age (year) & $51.24 \pm 11.9$ \\
\hline \multicolumn{2}{|l|}{ Sex } \\
\hline Male & $106(86.2 \%)$ \\
\hline Female & $17(13.8 \%)$ \\
\hline \multicolumn{2}{|l|}{ Smoke } \\
\hline Yes & $23(18.7 \%)$ \\
\hline No & $100(81.3 \%)$ \\
\hline \multicolumn{2}{|l|}{ Alcohol } \\
\hline Yes & $17(13.8 \%)$ \\
\hline No & $106(86.2 \%)$ \\
\hline \multicolumn{2}{|l|}{ Heart disease } \\
\hline Yes & $3(2.4 \%)$ \\
\hline No & $120(97.6 \%)$ \\
\hline \multicolumn{2}{|l|}{ Diabetes mellitus } \\
\hline Yes & $36(29.3 \%)$ \\
\hline No & $87(70.7 \%)$ \\
\hline \multicolumn{2}{|l|}{ Hypertension } \\
\hline Yes & $10(8.1 \%)$ \\
\hline No & $113(91.9 \%)$ \\
\hline \multicolumn{2}{|l|}{ HBV DNA (cps/ml) } \\
\hline $0-100$ & $51.2 \%)$ \\
\hline$>100$ & $60(48.8 \%)$ \\
\hline WBC & $8.18 \pm 16.63$ \\
\hline Platelet $\left(\times 10^{9} / \mathrm{L}\right)$ & $222.8 \pm 96.8$ \\
\hline Neutrophil $\left(\times 10^{9} / \mathrm{L}\right)$ & $4.34 \pm 2.81$ \\
\hline Lymphocyte $\left(\times 10^{9} / \mathrm{L}\right)$ & $1.48 \pm 0.64$ \\
\hline NLR & $3.96 \pm 4.53$ \\
\hline INR & $1.17 \pm 0.58$ \\
\hline Albumin (g/L) & $37.6 \pm 5.0$ \\
\hline \multicolumn{2}{|l|}{ a-fetoprotein (AFP) } \\
\hline $1-100$ & $77(62.6 \%)$ \\
\hline $101-400$ & $8.1 \%)$ \\
\hline$>400$ & $36(29.3 \%)$ \\
\hline Fibrinogen (g/L) & $3.70 \pm 1.27$ \\
\hline TBIL & $20.04 \pm 18.30$ \\
\hline DBIL & $9.26 \pm 11.98$ \\
\hline ALT (IU/L) & $123.4 \pm 40.0$ \\
\hline AST (IU/L) & $156.3 \pm 94.7$ \\
\hline Serum creatinine & $70.8 \pm 20.8$ \\
\hline Serum potassium & $4.02 \pm 0.50$ \\
\hline \multicolumn{2}{|l|}{ Cirrhosis } \\
\hline Yes & $63(48.8 \%)$ \\
\hline No & $63(51.2 \%)$ \\
\hline \multicolumn{2}{|l|}{ Portal hypertension } \\
\hline Yes & $37(30.1 \%)$ \\
\hline No & $86(69.9 \%)$ \\
\hline \multicolumn{2}{|c|}{ Oesophageal and gastric varices } \\
\hline Yes & $19(15.4 \%)$ \\
\hline No & $104(84.6 \%)$ \\
\hline Tumour size (mm) & $87.00 \pm 94.20$ \\
\hline \multicolumn{2}{|l|}{ Tumour count } \\
\hline 1 & $78(63.4 \%)$ \\
\hline $2-5$ & $19.5 \%)$ \\
\hline$>5$ & $21(17.1 \%)$ \\
\hline \multicolumn{2}{|c|}{ Extent of vascular invasion } \\
\hline $\mathrm{V} 1$ & $8(6.5 \%)$ \\
\hline $\mathrm{V} 2$ & $44(35.8 \%)$ \\
\hline V3 & $66(53.7 \%)$ \\
\hline $\mathrm{V} 4$ & $5(4.1 \%)$ \\
\hline \multicolumn{2}{|l|}{ Hilar lymphadenopathy } \\
\hline Yes & $36(29.3 \%)$ \\
\hline No & $87(70.7 \%)$ \\
\hline
\end{tabular}




\section{Characteristic}

Rupture

Yes $\quad 8(6.5 \%)$

No

$115(93.5 \%)$

WBC (white blood cell count), ALT (alanine aminotransferase), AST (aspartate aminotransferase), NLR (ratio of neutrophils to lymphocytes), TBIL (total

bilirubin), DBIL (direct bilirubin), HBV DNA (Hepatitis B Virus DNA load). A liver is defined as cirrhosis mainly according to the liver morphology. Irregularity of the liver surface, a great quantity of liver surface nodularity and sum of liver vein diameters divided by the caudate-right lobe ratio (ld/crl-r <24) indicate a cirrhotic liver. Portal hypertension, diameter of the portal vein (diameter $>13 \mathrm{~mm}$ ).

Table 2. Univariate and multivariate analysis for overall survival

\begin{tabular}{|c|c|c|c|c|c|c|}
\hline \multicolumn{4}{|l|}{ Univariate analysis } & \multicolumn{3}{|c|}{ Multivariate analysis } \\
\hline Variable & $\begin{array}{l}\text { Hazard } \\
\text { ratio }\end{array}$ & $95 \% \mathrm{CI}$ & $\begin{array}{l}\mathrm{P} \\
\text { value }\end{array}$ & $\begin{array}{l}\text { Hazard } \\
\text { ratio }\end{array}$ & $95 \% \mathrm{CI}$ & $\begin{array}{l}\mathrm{P} \\
\text { value }\end{array}$ \\
\hline Age (year) & 0.97 & $0.94-1.00$ & 0.04 & & & \\
\hline Sex & 1.30 & $0.54-3.11$ & 0.56 & & & \\
\hline Smoke & 1.61 & $0.76-3.41$ & 0.22 & & & \\
\hline Alcohol & 2.52 & $1.19-5.36$ & 0.02 & & & \\
\hline Heart disease & 3.02 & $0.72-12.67$ & 0.13 & & & \\
\hline Diabetes mellitus & 0.64 & $0.29-1.39$ & 0.26 & & & \\
\hline Hypertension & 1.88 & $0.73-4.82$ & 0.19 & & & \\
\hline HBV DNA (cps/ml) & 1.70 & $0.88-3.28$ & 0.11 & & & \\
\hline WBC & 0.99 & $0.96-1.02$ & 0.83 & & & \\
\hline Platelet $\left(\times 10^{9} / \mathrm{L}\right)$ & 1.00 & $1.00-1.00$ & 0.38 & & & \\
\hline Neutrophil $\left(\times 10^{9} / \mathrm{L}\right)$ & 1.09 & $1.03-1.16$ & 0.006 & & & \\
\hline Lymphocyte $\left(\times 10^{9} / \mathrm{L}\right)$ & 0.49 & $0.28-0.85$ & 0.01 & & & \\
\hline NLR & 1.06 & $1.02-1.10$ & 0.007 & & & \\
\hline INR & 1.24 & $0.91-1.68$ & 0.18 & & & \\
\hline Albumin (g/L) & 0.94 & $0.88-1.00$ & 0.06 & & & \\
\hline a-fetoprotein (AFP) & 1.00 & $1.00-1.00$ & 0.43 & & & \\
\hline Fibrinogen $(\mathrm{g} / \mathrm{L})$ & 1.25 & $1.08-1.45$ & 0.003 & 1.42 & $1.09-1.85$ & $<0.01$ \\
\hline TBIL & 1.00 & $0.98-1.02$ & 0.72 & & & \\
\hline DBIL & 1.00 & $0.97-1.03$ & 0.74 & & & \\
\hline $\operatorname{ALT}(\mathrm{IU} / \mathrm{L})$ & 1.00 & $1.00-1.00$ & 0.27 & & & \\
\hline AST (IU/L) & 1.00 & $1.00-1.00$ & 0.20 & & & \\
\hline Serum creatinine & 1.00 & $0.98-1.02$ & 0.92 & & & \\
\hline Serum potassium & 3.58 & $2.06-6.22$ & 0.000 & 2.08 & $1.41-3.06$ & $<0.01$ \\
\hline Cirrhosis & 0.84 & $0.44-1.61$ & 0.60 & & & \\
\hline Portal hypertension & 1.27 & $0.64-2.53$ & 0.49 & & & \\
\hline $\begin{array}{l}\text { Oesophageal and gastric } \\
\text { varices }\end{array}$ & 0.89 & $0.36-2.28$ & 0.80 & & & \\
\hline Tumour size (mm) & 1.00 & $1.00-1.00$ & 0.07 & & & \\
\hline $\begin{array}{l}\text { Extent of vascular } \\
\text { invasion }\end{array}$ & 4.33 & $2.36-7.93$ & 0.000 & 3.39 & $1.85-6.21$ & $<0.01$ \\
\hline Tumour count & 1.47 & $1.01-2.16$ & 0.04 & 2.20 & $1.03-4.70$ & 0.04 \\
\hline Rupture & 1.18 & $0.36-3.83$ & 0.79 & & & \\
\hline Hilar lymphadenopathy & 1.09 & $0.54-2.20$ & 0.82 & & & \\
\hline
\end{tabular}

The OS and RFS nomograms can be used to predict OS and RFS at 1 year and 3 years (Figure 1). The performance of the predictive nomogram in our cohort was evaluated by two methods. First, the C-index was assessed to quantify the discrimination among individual patients. The C-indices of the two nomograms were 0.80 and 0.69 for OS and RFS, respectively, indicating a good discriminative ability (ability to distinguish between patients who have had an event from those who have not). The C-indices of the bootstrap validation were 0.81 and 0.69 , respectively. Furthermore, we split the patients randomly into $70 \%$ cases for development and 30\% cases for validation. For OS nomogram (70\% cases for development, $30 \%$ for validation): When using $70 \%$ cases for development, the C-index of the model is 0.82 . When the model is used for validation cohort, the total point show a significant effect to predict overall survival $(p=0.001)$. The $\mathrm{C}$-index is 0.76 . For RFS nomogram (70\% cases for development, 30\% for validation): When using $70 \%$ cases for development, the C-index of the model is 0.71 . When the model is used for validation cohort, the total point show a significant effect to predict recurrence-free survival $(p=0.002)$. The $C$-index is 0.75 . Second, the calibration plots compared the nomogram-predicted probabilities of OS and RFS with the observed rate at 1 and 3 years (Figure 2). The performance of the ideal nomogram, in which the predicted outcome would perfectly overlap with the actual outcome, was plotted as a dotted line. The solid line represents the performance of the nomogram in predicting the OS and RFS probability of our HCC patients with MaVI. The calibration plots show that actual survival corresponded closely to the nomogram-predicted survival probabilities.

Table 3. Univariate and multivariate analysis for recurrence free survival

\begin{tabular}{|c|c|c|c|c|c|c|}
\hline \multicolumn{4}{|l|}{ Univariate analysis } & \multicolumn{3}{|c|}{ Multivariate analysis } \\
\hline Variable & $\begin{array}{l}\text { Hazard } \\
\text { ratio }\end{array}$ & $95 \% \mathrm{CI}$ & $\begin{array}{l}\mathrm{P} \\
\text { value }\end{array}$ & $\begin{array}{l}\text { Hazard } \\
\text { ratio }\end{array}$ & $95 \% \mathrm{CI}$ & $\begin{array}{l}\mathrm{P} \\
\text { value }\end{array}$ \\
\hline Age (year) & 0.98 & $0.97-1.00$ & 0.11 & & & \\
\hline Sex & 0.79 & $0.41-1.54$ & 0.50 & & & \\
\hline Smoke & 1.32 & $0.78-2.26$ & 0.30 & & & \\
\hline Alcohol & 1.09 & $0.57-2.05$ & 0.80 & & & \\
\hline Heart disease & 2.77 & $0.86-8.92$ & 0.09 & & & \\
\hline Diabetes mellitus & 0.86 & $0.53-1.40$ & 0.55 & & & \\
\hline Hypertension & 1.19 & $0.57-2.46$ & 0.65 & & & \\
\hline HBV DNA (cps/ml) & 1.82 & $1.17^{*} 2.82$ & 0.008 & 1.74 & $1.10-2.75$ & 0.02 \\
\hline WBC & 1.00 & $1.00-1.02$ & 0.20 & & & \\
\hline Platelet $\left(\times 10^{9} / \mathrm{L}\right)$ & 1.00 & $1.00-1.00$ & 0.20 & & & \\
\hline Neutrophil $\left(\times 10^{9} / \mathrm{L}\right)$ & 1.04 & $0.98-1.11$ & 0.18 & & & \\
\hline Lymphocyte $\left(\times 10^{9} / \mathrm{L}\right)$ & 0.87 & $0.62-1.22$ & 0.42 & & & \\
\hline NLR & 1.02 & $0.98-1.06$ & 0.35 & & & \\
\hline INR & 1.24 & $0.91-1.68$ & 0.18 & & & \\
\hline Albumin $(\mathrm{g} / \mathrm{L})$ & 1.00 & $1.00-1.00$ & 0.30 & & & \\
\hline a-fetoprotein (AFP) & 0.94 & $0.73-1.20$ & 0.63 & & & \\
\hline Fibrinogen $(\mathrm{g} / \mathrm{L})$ & 1.12 & $0.98-1.26$ & 0.09 & & & \\
\hline TBIL & 1.01 & $1.00-1.02$ & 0.05 & & & \\
\hline DBIL & 1.02 & $0.99-1.03$ & 0.06 & & & \\
\hline $\operatorname{ALT}(\mathrm{IU} / \mathrm{L})$ & 1.00 & $1.00-1.00$ & 0.55 & & & \\
\hline AST (IU/L) & 1.00 & $1.00-1.00$ & 0.52 & & & \\
\hline Serum creatinine & 1.00 & $1.00-1.02$ & 0.29 & & & \\
\hline Serum potassium & 2.00 & $1.28-3.14$ & 0.002 & 1.35 & $1.01-1.80$ & 0.04 \\
\hline Cirrhosis & 0.90 & $0.58-1.39$ & 0.63 & & & \\
\hline Portal hypertension & 0.84 & $0.52-1.38$ & 0.50 & & & \\
\hline $\begin{array}{l}\text { Oesophageal and gastric } \\
\text { varices }\end{array}$ & 0.82 & $0.43-1.60$ & 0.57 & & & \\
\hline Tumour size (mm) & 1.00 & $1.00-1.00$ & 0.21 & & & \\
\hline $\begin{array}{l}\text { Extent of vascular } \\
\text { invasion }\end{array}$ & 1.65 & $1.17-2.30$ & 0.004 & 1.49 & $1.04-2.11$ & 0.03 \\
\hline Tumour count & 1.54 & $1.19-1.99$ & 0.001 & 2.27 & $1.35-3.85$ & $<0.01$ \\
\hline Rupture & 1.24 & $0.54-2.86$ & 0.61 & & & \\
\hline Hilar lymphadenopathy & 1.00 & $0.62-1.61$ & 0.99 & & & \\
\hline
\end{tabular}



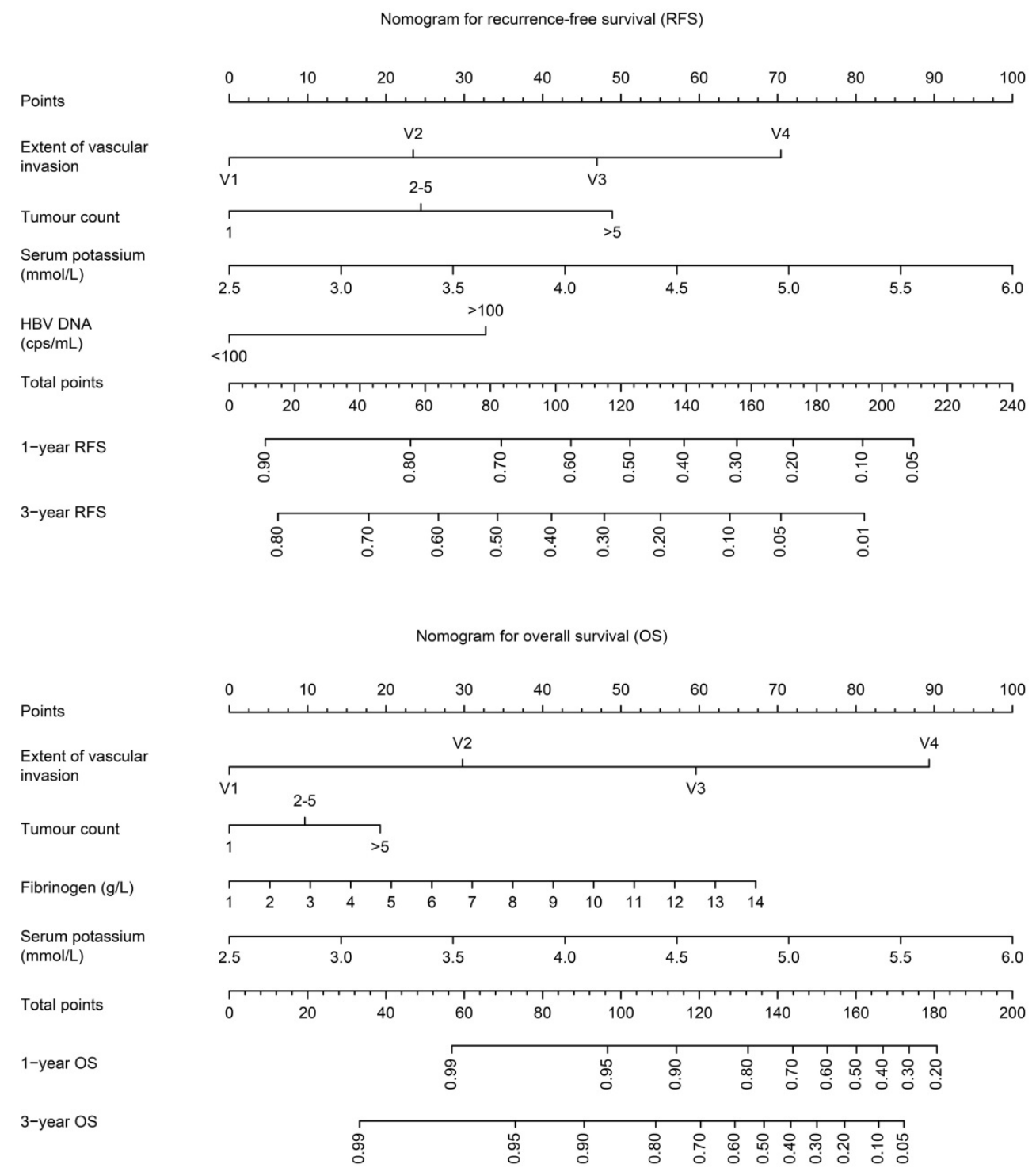

Figure 1: Nomograms for RFS and OS. The nomograms provide a method to calculate 1-year and 3-year OS and RFS after hepatic resection for HCC patients with MaVI, on the basis of a patient's combination of covariates. To use, locate the patient's tumour count, draw a line straight up to the points axis to establish the score associated with that count. Repeat for the other three covariates. Add the score of each covariate together and locate the total score on the total points axis. Draw a line straight down to the 1 -year and 3-year OS or RFS to obtain the probability.

\section{Discussion}

MaVI poses a clinical dilemma due to its close relationship with post-treatment tumour recurrence and poor survival in HCC patients. Among the HCC patients with MaVI, the 1-year and 3-year survival rates for those receiving local ablation were approximately $75 \%$ and $51 \%$, respectively, and approximately $57 \%$ and $41 \%$, respectively, for those receiving transarterial chemoembolization. ${ }^{18}$ According to the SHARP trial, the median survival for patients receiving sorafenib was approximately 8.1 months. ${ }^{19}$ The prognosis of HCC with MaVI is discouraging.

Because local ablation, transarterial chemoembolization and systemic chemotherapy have not been shown to provide satisfied survival benefit and because the natural history of untreated disease typically leads to death within months, surgical treatment may be a therapeutic option that offer more survival benefit. ${ }^{3,20-22}$ However, the current staging system remains unable to select patients who will benefit most from hepatic resection. Currently, the real need is to be able to identify which HCC patients with MaVI will require surgery.

We identified important multivariate predictors of survival for HCC patients with MaVI and proposed a prognostic model using only known preoperative factors to help select HCC patients with MaVI for hepatic resection. Additionally, we developed novel comprehensive clinicopathologic prognostic nomograms that accurately predict an individual patient's survival and may be used as a reference in deciding whether to operate. We believe that having 

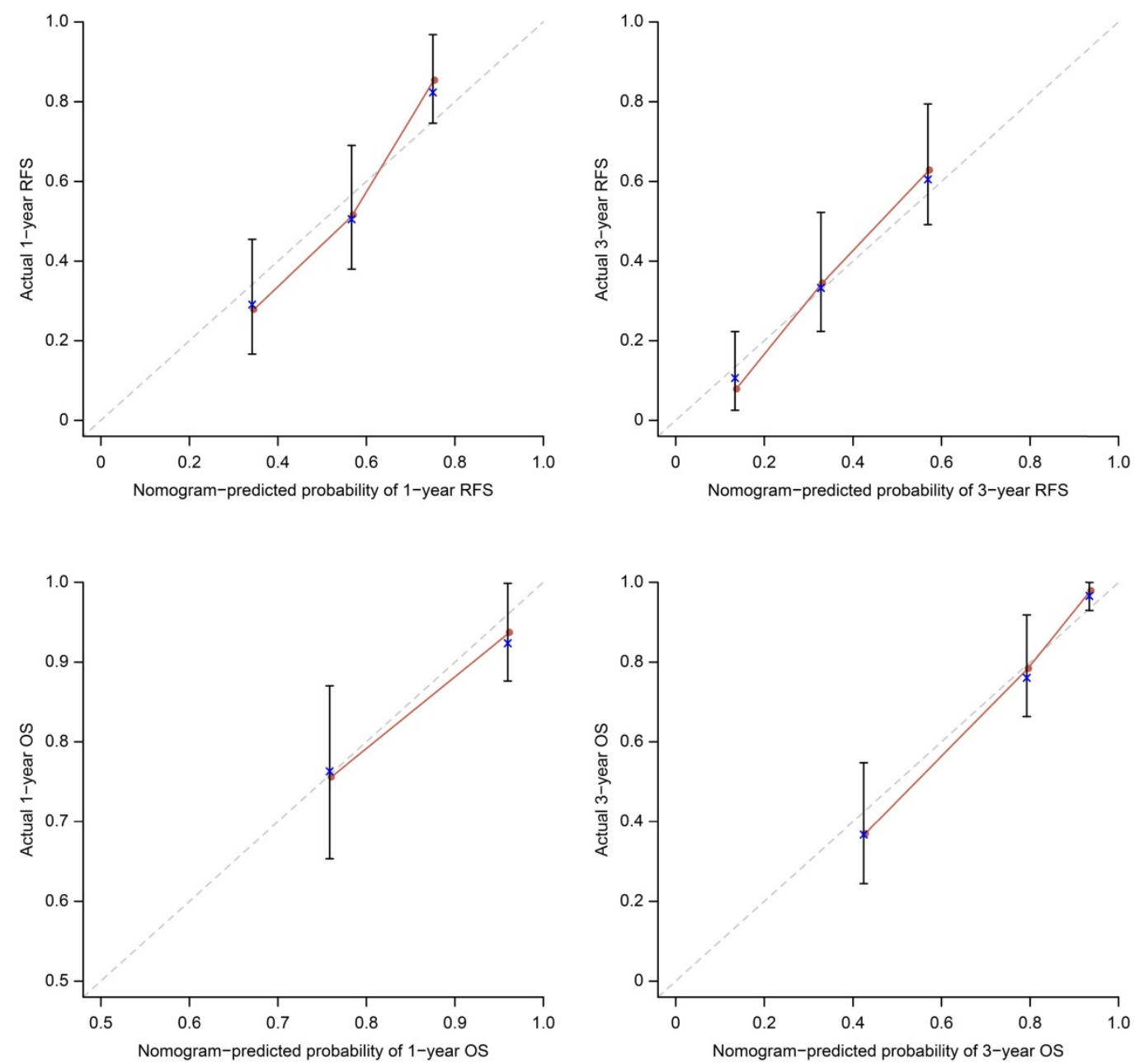

Figure 2: Calibration plots for the nomograms. The average predicted probability (nomogram-predicted survival; $x$-axis) was plotted against the Kaplan-Meier estimate (actual survival; $y$-axis). $95 \% \mathrm{Cls}$ of the Kaplan-Meier estimates are indicated with vertical lines. Dashed line indicates the reference line, indicating where an ideal nomogram would lie.

two nomograms, one for overall survival and one for recurrence free survival, might add to their clinical value. In the present study, multivariate analysis of prognostic factors for survival after surgery in patients with HCC and MaVI indicated that the extent of vascular invasion, tumour count, serum fibrinogen, HBV DNA and serum potassium were significantly associated with patient prognosis.

In work by Lee et al., HCC patients with MaVI had 1-year and 3-year OS rates of $83 \%$ and $68 \%$, respectively. ${ }^{18}$ In our database, HCC patients with MaVI had 1-year and 3-year OS rates of $84 \%$ and $71 \%$, respectively, similar to the results of Lee et al. In some recent studies, HCC patients without MaVI had 1-year and 3-year RFS rates of $76-90 \%$ and $41-61 \%$, respectively. ${ }^{23-25}$ Based on our predictive model, patients with predictive 1-year and 3-year RFS rates of more than $80 \%$ and $56 \%$ had actual 1-year and 3-year RFS rates of $81.8 \%$ and $57.1 \%$, respectively, including $9.0 \%$ and $17.1 \%$ of the HCC patients with MaVI. As described above, these results indicate that certain HCC patients with MaVI can benefit from hepatic resection, with the same RFS rate as patients without MaVI. Patients with a predictive 3-year RFS rate below $20 \%$ had an actual 3-year RFS rate of $7.1 \%$, including $22.8 \%$ of the HCC patients with MaVI, which suggests that these patients have a high probability of recurrence within 1 year and should not be offered hepatic resection.

Yoshidome et al. have reported that patients with HCC invading the main trunk/the first-order branch of the portal vein $(\mathrm{Vp} 4 / 3)$ or the inferior vena cava (Vv3) had poorer survival rates after surgical treatment than patients showing invasion of the more peripheral branch of the portal vein or the hepatic vein. ${ }^{26}$ Roayaie et al. ${ }^{6}$ have also found that the extent of vascular invasion was independently associated with 90-day perioperative mortality $(p<0.001)$. In our study, the 3-year OS and RFS rate of the V3 plus V4 group were $56.9 \%$ and $25.0 \%$ respectively; the 3-year OS and RFS rate of the V1 plus V2 group were $90.2 \%$ and $51.0 \%$ respectively, indicating that tumour invasion of the distant branch of the portal vein or hepatic vein (V1) or first branch of the hepatic vein or 
the second branch of the portal vein (V2) may have a relative good prognosis.

Yoshidome et al. reported that HCC patients who had good treatment results with a tumour size measuring less than $10 \mathrm{~cm}$ in diameter appeared to have favourable outcomes after surgical treatment. ${ }^{26}$ Roayaie et $a .^{6}$ have observed that tumour size was independently associated with survival. Pawlik et al. have stated that moderate to severe fibrosis (Ishak grades 3 to 6) remained an independent predictor of poor survival in HCC patients with MaVI. ${ }^{27}$ However, in our study, tumour size and cirrhosis were not significantly correlated with survival. Tsai et al. ${ }^{28}$ have observed that tumour size was closely correlated with both microscopic and macroscopic vascular invasion. The fact that tumour size may be a marker of vascular invasion may explain why tumour size failed to affect patient survival in our study, which controlled for vascular invasion. ${ }^{29-32}$ Additionally, liver cirrhosis may become more pronounced over time, particularly with 5 or more years of survival. ${ }^{33}$ Our study focused on 1- and 3-year survival, which may explain why cirrhosis failed to affect survival in our study.

Some recent studies have also shown that HCC recurrence is associated with a high HBV-DNA load. ${ }^{34-40}$ In our study, HBV DNA copies correlated with RFS, perhaps because HBV replication accelerates in $\mathrm{HBV}$ reactivation, thereby resulting in liver injury and influencing recurrence. Some studies have also shown that high plasma fibrinogen levels are associated with advanced stage HCC and poorer long-term overall survival, ${ }^{41,42}$ which aligned with our study.

Notably, the serum potassium level was correlated with OS and RFS in our study. Few studies have correlated serum potassium with HCC prognosis. Yang et al. demonstrated that IKCa1 mRNA expression in HCC tissues was 2.17 times higher than that in paracancerous tissues [43]. Casadei Gardini et al. [44] also reported reduced serum potassium levels in HCC patients who responded to sorafenib. Potassium channels may affect proliferation, the cell cycle or apoptosis in cancer cells by regulating membrane potential or by modifying intracellular signals.

The present study has a few limitations. First, only a few patients underwent surgical treatment, leading to a small sample size because most of the HCC patients with MaVI received palliative treatment. Second, external validation of this predictive model is unavailable at the moment.

In conclusion, surgical treatment is now a therapeutic option that may provide more survival benefit in HCC patients with MaVI. We developed novel, comprehensive clinicopathologic prognostic nomograms that accurately predict individual patient survival. With the help of our nomograms, selected HCC patients with MaVI can benefit from hepatic resection with the same survival rates as patients without MaVI.

\section{Abbreviations}

HCC, Hepatocellular carcinoma; MaVI, Macroscopic vascular invasion; BCLC, Barcelona Clinic Liver Cancer; CT, computed tomography; MRI, magnetic resonance imaging; OS, overall survival; RFS, recurrence free survival; HR, hazard ratio; CI, confidence interval; HBV DNA, Hepatitis B Virus DNA load.

\section{Acknowledgements}

This study was supported by the National Natural Science Foundation of China (No. 81470870, 81670601, 81570593), Guang-dong Natural Science Foundation(No. 2015A030312013，2015A030313038), Sci-tech Research Development Program of Guangdong Province (2014B020228003, 2017B020209004), Sci-tech Research Development Program of Guangzhou city (No. 201508020262, 201400000001-3, 201604020001, 201607010024), and National 13th Five-Year Science and Technology Plan Major Projects of China (2017ZX10203205-006).

Yiquan Jiang made the main contributions to conception and design, and acquisition of data, and analysis and interpretation of data; and participated in drafting the article or revising it critically for important intellectual content. Hui Tang make substantial contributions to conception and design; and acquisition of data; Wei Meng, Guoying Wang, Hua Li, Shuhong Yi, Genshu Wang make substantial contributions to conception and design; Guihua Chen, Guoying Wang, Yang Yang give final approval of the version to be submitted and any revised version.

We thanks for the English and format editing by American Journal Experts Company.

\section{Competing Interests}

The authors have declared that no competing interest exists.

\section{References}

1. Sherman M. Hepatocellular Carcinoma: Epidemiology, Surveillance, and Diagnosis. Semin Liver Dis 2010; 30: 3-16.

2. Ferlay J, Shin HR, Bray F, et al. Estimates of Worldwide Burden of Cancer in 2008: GLOBOCAN 2008. Int J Cancer 2010; 127: 2893-917.

3. Llovet JM, Bustamante J, Castells A, et al. Natural history of untreated nonsurgical hepatocellular carcinoma: rationale for the design and evaluation of therapeutic trials. Hepatology 1999; 29: 62-7.

4. Villa E, Moles A, Ferretti I, et al. Natural history of inoperable hepatocellular carcinoma: estrogen receptors' status in the tumor is the strongest prognostic factor for survival. Hepatology 2000; 32: 233-8.

5. Cabibbo G, Enea M, Attanasio M, et al. A meta-analysis of survival rates of untreated patients in randomized clinical trials of hepatocellular carcinoma. Hepatology 2010; 51: 1274-83. 
6. Roayaie S, Jibara G, Taouli B, Schwartz M. Resection of hepatocellular carcinoma with macroscopic vascular invasion. Ann Surg Oncol 2013; 20: 3754-60.

7. Bruix J, Sherman M, American Association for the Study of Liver Diseases. Management of Hepatocellular Carcinoma: An Update. Hepatology 2011; 53: 1020-2.

8. European Association For The Study Of The Liver, Research EOF, Treatment Of Cancer. EASL-EORTC Clinical Practice Guidelines: Management of Hepatocellular Carcinoma. J Hepatol 2012; 56: 908-43.

9. Ishizawa T, Hasegawa K, Aoki T, et al. Neither multiple tumors nor portal hypertension are surgical contraindications for hepatocellular carcinoma. Gastroenterology 2008; 134: 1908-16

10. Torzilli G, Belghiti J, Kokudo N, et al. A Snapshot of the Effective Indications and Results of Surgery for Hepatocellular Carcinoma in Tertiary Referral Centers: Is it Adherent to the EASL/AASLD Recommendations? An Observational Study of the HCC East-West Study Group. Ann Surg 2013; 257: 929-37.

11. Zhong JH, Ke Y, Gong WF, et al. Hepatic resection associated with good survival for selected patients with intermediate and advanced-stage hepatocellular carcinoma. Ann Surg 2014; 260: 329-40.

12. Zhong JH, Xiang BD, Gong WF, et al. Comparison of long-term survival of patients with BCLC stage B hepatocellular carcinoma after liver resection or transarterial chemoembolization. PLoS One 2013; 8: e68193.

13. Zhong JH, Rodriguez AC, $\mathrm{Ke} Y$, et al. Hepatic Resection as a Safe and Effective Treatment for Hepatocellular Carcinoma Involving a Single Large Tumor, Multiple Tumors, or Macrovascular Invasion. Medicine (Baltimore) 2015; 94: e396.

14. Livraghi $T$, Brambilla $G$, Carnaghi $C$, et al. Is it time to reconsider the BCLC/AASLD therapeutic flow-chart? J Surg Oncol 2010; 102: 868-76.

15. Agrawal S, Belghiti J. Oncologic resection for malignant tumors of the liver. Ann Surg 2011; 253: 656-65.

16. Andreou A, Vauthey JN, Cherqui D, et al. Improved Long-Term Survival After Major Resection for Hepatocellular Carcinoma: A Multicenter Analysis Based on a New Definition of Major Hepatectomy. J Gastrointest Surg 2013; 17: 66-77.

17. Zhang T, Huang JW, Bai YN, et al. Recurrence and survivals following hepatic resection for hepatocellular carcinoma with major portal/hepatic vein tumor thrombus. Hepatol Res 2014; 44: 761-8.

18. Lee $\mathrm{YH}, \mathrm{Hsu} \mathrm{CY}$, Huang $\mathrm{YH}$, et al. Vascular Invasion in Hepatocellular Carcinoma: Prevalence, Determinants and Prognostic Impact. J Clin Gastroenterol 2014; 48: 734-41.

19. Bruix J, Raoul JL, Sherman M, et al. Efficacy and Safety of Sorafenib in Patients with Advanced Hepatocellular Carcinoma: Subanalyses of a Phase III Trial. J Hepatol 2012; 57: 821-9.

20. Herrero JI, Sangro B, Quiroga J, et al. Influence of Tumor Characteristics on the Outcome of Liver Transplantation Among Patients with Liver Cirrhosis and Hepatocellular Carcinoma. Liver Transpl 2001; 7: 631-6.

21. Mazzaferro V, Regalia E, Doci R, et al. Liver Transplantation for the Treatment of Small Hepatocellular Carcinomas in Patients with Cirrhosis. N Engl J Med 1996; 334: 693-9.

22. Pawarode A, Voravud N, Sriuranpong V, et al. Natural History of Untreated Primary Hepatocellular Carcinoma: A Retrospective Study of 157 Patients. Am Clin Oncol 1998; 21: 386-91.

23. Zhao $\mathrm{H}, \mathrm{Chen} \mathrm{C}, \mathrm{Gu} \mathrm{S}$, et al. Anatomical versus non-anatomical resection for solitary hepatocellular carcinoma without macroscopic vascular invasion: A propensity score matching analysis. J Gastroenterol Hepatol 2017; 32: 870-8

24. Huang J, Yan L, Cheng Z, et al. A randomized trial comparing radiofrequency ablation and surgical resection for HCC conforming to the Milan criteria. Ann Surg 2010; 252: 903-12.

25. Fang Y, Chen W, Liang X, et al. Comparison of long-term effectiveness and complications of radiofrequency ablation with hepatectomy for small hepatocellular carcinoma. J Gastroenterol Hepatol 2014; 29: 193-200.

26. Yoshidome H, Takeuchi D, Kimura F, et al. Treatment Strategy for Hepatocellular Carcinoma with Major Portal Vein or Inferior Vena Cava Invasion: A Single Institution Experience. J Am Coll Surg 2011; 212: 796-803.

27. Pawlik TM, Poon RT, Abdalla EK, et al. Hepatectomy for Hepatocellular Carcinoma with Major Portal or Hepatic Vein Invasion: Results of a Multicenter Study. Surgery 2005; 137: 403-10.

28. Tsai TJ, Chau GY, Lui WY, et al. Clinical Significance of Microscopic Tumor Venous Invasion in Patients with Resectable Hepatocellular Carcinoma. Surgery 2000; $127: 603-8$

29. el-Assal ON, Yamanoi A, Soda Y, et al. Proposal of Invasiveness Score to Predict Recurrence and Survival After Curative Hepatic Resection for Hepatocellular Carcinoma. Surgery 1997; 122: 571-7.

30. Fong Y, Sun RL, Jarnagin W, Blumgart LH. An Analysis of 412 Cases of Hepatocellular Carcinoma at a Western Center. Ann Surg 1999; 229: 790.

31. Kosuge T, Makuuchi M, Takayama T, et al. Long-Term Results After Resection of Hepatocellular Carcinoma: Experience of 480 Cases. Hepatogastroenterology 1993; 40: 328-32.

32. Vauthey JN, Klimstra D, Franceschi D, et al. Factors Affecting Long-Term Outcome After Hepatic Resection for Hepatocellular Carcinoma. Am J Surg 1995; 169: 28-35.

33. Vauthey JN, Lauwers GY, Esnaola NF, et al. Simplified staging for hepatocellular carcinoma. J Clin Oncol 2002; 20: 1527-36.
34. An HJ, Jang JW, Bae SH, et al. Sustained low hepatitis B viral load predicts good outcome after curative resection in patients with hepatocellular carcinoma. J Gastroenterol Hepatol 2010; 25: 1876-82.

35. Hoshida Y. Risk of recurrence in hepatitis B-related hepatocellular carcinoma: impact of viral load in late recurrence. J Hepatol 2009; 51: 842-4.

36. Huang G, Lai EC, Lau WY, et al. Posthepatectomy HBV reactivation in hepatitis B-related hepatocellular carcinoma influences postoperative survival in patients with preoperative low HBV-DNA levels. Ann Surg 2013; 257: 490-505

37. Hung IF, Poon RT, Lai CL, et al. Recurrence of hepatitis B-related hepatocellular carcinoma is associated with high viral load at the time of resection. Am J Gastroenterol 2008; 103: 1663-73.

38. Kubo S, Hirohashi K, Tanaka H, et al. Virologic and biochemical changes and prognosis after liver resection for hepatitis B virus-related hepatocellular carcinoma. Dig Surg 2001; 18: 26-33.

39. Qu LS, Jin F, Huang XW, Shen XZ. High hepatitis B viral load predicts recurrence of small hepatocellular carcinoma after curative resection. J Gastrointest Surg 2010; 14: 1111-20.

40. Wang Q, Lin L, Yoo S, et al. Impact of non-neoplastic vs intratumoural hepatitis B viral DNA and replication on hepatocellular carcinoma recurrence. Br J Cancer 2016; 115: 841-7.

41. Kinoshita A, Onoda H, Imai N, et al. Elevated plasma fibrinogen levels are associated with a poor prognosis in patients with hepatocellular carcinoma. Oncology 2013; 85: 269-77.

42. Zhang X, Long Q. Elevated serum plasma fibrinogen is associated with advanced tumor stage and poor survival in hepatocellular carcinoma patients. Medicine (Baltimore) 2017; 96: e6694.

43. Yang XW, Liu JW, Zhang RC, et al. Inhibitory effects of blockage of intermediate conductance $\mathrm{Ca}(2+)$-activated $\mathrm{K}(+)$ channels on proliferation of hepatocellular carcinoma cells. J Huazhong Univ Sci Technolog Med Sci 2013; 33: 86-9.

44. Casadei Gardini A, Scarpi E, Marisi G, et al. Early onset of hypertension and serum electrolyte changes as potential predictive factors of activity in advanced HCC patients treated with sorafenib: results from a retrospective analysis of the HCC-AVR group. Oncotarget 2016; 7: 15243-51. 